\title{
Tip Jets and Barrier Winds: A QuikSCAT Climatology of High Wind Speed Events around Greenland
}

\author{
G. W. K. MoOre \\ Department of Physics, University of Toronto, Toronto, Ontario, Canada \\ I. A. RENFREW \\ School of Environmental Sciences, University of East Anglia, Norwich, United Kingdom
}

(Manuscript received 28 September 2004, in final form 18 January 2005)

\begin{abstract}
The high topography of Greenland results in a number of orographically induced high wind speed flows along its coast that are of interest from both a severe weather and climate perspective. Here the surface wind field dataset from the NASA-JPL SeaWinds scatterometer on board the Quick Scatterometer (QuikSCAT) satellite is used to develop a wintertime climatology of these flows. The high spatial resolution and the twice-daily sampling of the SeaWinds instrument allows for a much more detailed view of the surface winds around Greenland than has been previously possible. Three phenomena stand out as the most distinctive features of the surface wind field during the winter months: the previously identified tip jets and reverse tip jets, as well as the hitherto unrecognized barrier flows along its southeast coast in the vicinity of the Denmark Strait. Peak surface wind speeds associated with these phenomena can be as large as $50 \mathrm{~m} \mathrm{~s}^{-1}$ with winds over $25 \mathrm{~m} \mathrm{~s}^{-1}$ occurring approximately $10 \%-15 \%$ of the time at each location.

A compositing technique is used to show that each type of flow is the result of an interaction between a synoptic-scale parent cyclone and the high topography of Greenland. In keeping with previous work, it is argued that tip jets are caused by a combination of conservation of the Bernoulli function during orographic descent and acceleration due to flow splitting as stable air passes around Cape Farewell, while barrier winds are a geostrophic response to stable air being forced against high topography. It is proposed that reverse tip jets occur when barrier winds reach the end of the topographic barrier and move from a geostrophic to a gradient wind balance, becoming supergeostrophic as a result of their anticyclonic curvature.
\end{abstract}

\section{Introduction}

Knowledge of the near-surface marine wind field is important for many meteorological, oceanographic, climatological, and wind energy applications. Strong surface winds over the ocean are of particular importance as they, along with the associated wave field, represent a significant hazard to maritime activity (Khandekar and Swail 1995; Del Prete et al. 1999). High surface wind speeds are also associated with enhanced air-sea fluxes of heat, moisture, and momentum that are of importance for the forcing of ocean currents (Bacon 1997; Spall and Pickart 2003) and the triggering of

Corresponding author address: Dr. G. W. K. Moore, Department of Physics, University of Toronto, 60 St. George St., Toronto, ON M5S 1A7, Canada.

E-mail: moore@atmosp.physics.utoronto.ca ocean convection (Lab Sea Group 1998; Renfrew et al. 2002). In coastal regions, high winds contribute to erosion (Lynch et al. 2003) as well as being an increasingly important energy resource (Barthelmie and Pryor 2003).

As a result of its high topography and ice-covered surface, Greenland plays a significant role in the weather and climate of the North Atlantic (Scorer 1988; Kristjansson and McInnes 1999; Petersen et al. 2003) as well having an impact on the general circulation of the Northern Hemisphere (Petersen et al. 2004). The surface wind stress in the vicinity of Greenland plays a role in the forcing of the East Greenland Current (Bacon 1997; Spall and Price 1998) as well as in cyclonic recirculation gyres in the Irminger and Labrador Seas (Lavender et al. 2000; Spall and Pickart 2003). Deep ocean convection occurs in both the Labrador and Irminger Seas, with high wind speeds being crucial for the large 

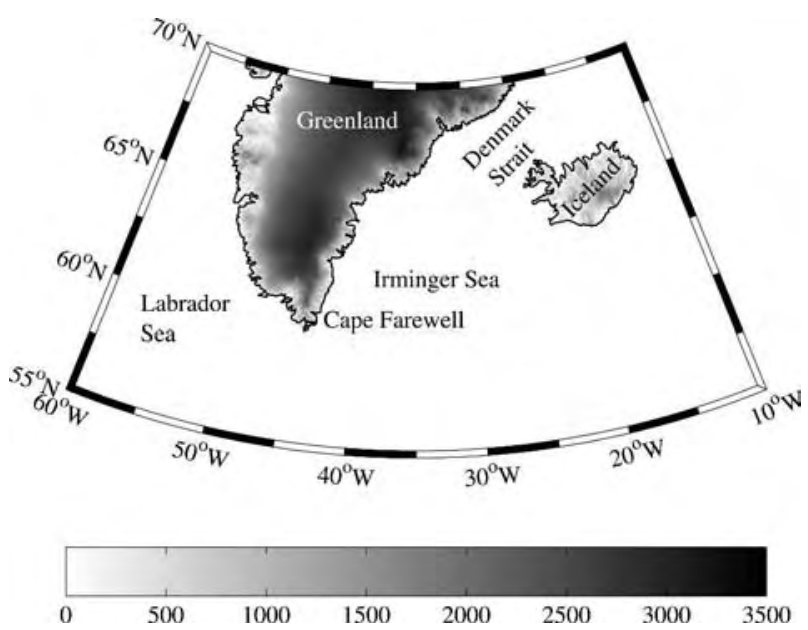

FIG. 1. Map showing the topography $(\mathrm{m})$ in the region of interest for this study.

air-sea heat and moisture exchanges that densify the surface waters and drive convection (Lab Sea Group 1998; Bacon et al. 2003; Pickart et al. 2003a,b). Please refer to Fig. 1 for a map of the region of interest.

High winds associated with mesoscale cyclogenesis are known to occur over the Labrador Sea (Mailhot et al. 1996; Moore et al. 1996; Rasmussen et al. 1996; Moore and Vachon 2002) as well as over the Irminger and Greenland Seas (Douglas et al. 1995; Klein and Heinemann 2002; Mills and Anderson 2003). In all of these regions, there exists evidence that the interactions of synoptic-scale features with the high topography of Greenland contribute to the development of mesoscale cyclones (Klein and Heinemann 2002; Moore and Vachon 2002; Mills and Anderson 2003). For example, Klein and Heinemann show that mesoscale cyclones are often spawned on the southeast coast of Greenland, around $65^{\circ} \mathrm{N}$, as a result of cyclonic vorticity generated through vortex stretching as katabatic flow descends to the sea. Through idealized and case study numerical modeling experiments they showed that the location of cyclogenesis is tied to the topography of Greenland. A background state consisting of a synoptic-scale low pressure system to the east of Greenland was necessary, although mesoscale cyclogenesis was not sensitive to the location of this low.

Doyle and Shapiro (1999) investigated the dynamics of intense low-level westerly jets, known as a tip jets, that develop east of Cape Farewell. They argued, through idealized and case study numerical simulations, that tip jets are governed by conservation of the Bernoulli function as air parcels accelerate down the lee slope during orographic descent. They found that the strength of the tip jet was a function of the upstream Froude number (equivalently the dimensionless ob- stacle height) and the Rossby number. In other words, the tip jet structure depended upon details of the splitting that occurs when a flow impinges on a mountain barrier (Olafsson and Bougeault 1996; Petersen et al. 2003). There exists anecdotal evidence that strong easterly winds also occur near Cape Farewell (Mertins 1976), and that Denmark Strait, separating Iceland from Greenland, is a region of high winds (Scorer 1988). Neither of these phenomenon have received much attention or concerted study.

Despite the importance and rich spectrum of high wind speed events that are associated with the dramatic topography of Greenland, there have been remarkably few climatological studies in this area, perhaps in part due to the paucity of in situ observations. Isemer and Hasse (1991) presented mean and variance fields for the January $10-\mathrm{m}$ wind speed field over the North Atlantic. Unfortunately, results were not presented north of $65^{\circ} \mathrm{N}$, presumably due to the reduction in the density of observations that occurs as one move poleward (Bunker 1976). The maximum January mean 10-m wind speeds, in excess of $13 \mathrm{~m} \mathrm{~s}^{-1}$, were localized in three main regions: the Labrador Sea, directly south of Cape Farewell, and upwind of the British Isles. They made use of a Weibull distribution (Hennessey 1977; Pavia and O'Brien 1986) to describe the statistics of the $10-\mathrm{m}$ wind speed field over the North Atlantic. An appealing characteristic of this distribution is its ability to describe so-called heavy-tailed distributions in which the probability of observing extreme events is enhanced compared to a more traditional Gaussian distribution (Hennessey 1977; Ross 1995). They identified a region south of Cape Farewell where the shape parameter of the Weibull distribution was large, indicating that the probability of observing high winds was elevated.

Moore (2003) used the 10-m wind field from the National Centers for Environmental Prediction (NCEP) reanalysis to develop a climatology of high wind speed events near Cape Farewell. He found that the zonal wind in this region was bimodal with an increased probability of observing both westerly and easterly high wind speed events. Through a composite analysis, the westerly high wind speed events were found to be associated with tip jets of the type identified by Doyle and Shapiro (1999), while the easterly events represented a new phenomenon dubbed "reverse tip jets." The event described by Mertins (1976) was most likely an example of a reverse tip jet. Both classes of high wind speed events were found to be associated with the interaction of a synoptic-scale cyclone with the high topography of southern Greenland. For tip jet events, the cyclones were situated to the northeast of Cape Farewell, while for reverse tip jet events, the cyclones were situated to 
the south of Cape Farewell. The frequency of occurrence of these high wind events was found to be modulated by the phase of the North Atlantic Oscillation with tip jets being more common during its positive phase and reverse tip jets being more common during its negative phase (Moore 2003).

Moore (2003) also noted a region of high wind constancy along the southeast coast of Greenland that was attributed to the presence of barrier flow in the region. Such winds develop when low Froude number flow interacts with high topography (Olafsson and Bougeault 1996; King and Turner 1997). The flow is unable to cross the topographic barrier resulting in a damming of cold air and the generation of a potential temperature gradient (i.e., a pressure gradient) perpendicular to the barrier. This pressure gradient supports a geostrophically balanced flow, or barrier wind, that is directed with the barrier to its right in the Northern Hemisphere. Barrier winds have been documented on the eastern side of the Antarctic Peninsula where they are associated with cold temperatures, strong winds, and the northward movement of sea ice in the western Weddell Sea (Schwerdtfeger 1975; Parish 1983). At the northern tip of the Antarctic Peninsula there is evidence that the elimination of the topographically induced pressure gradient results in a transition from geostrophic to cyclostrophic balance and the concomitant formation of an anticyclonic jet in the adjoining Bransfield Strait (Parish and Schwerdtfeger 1977; Parish 1983). Barrier winds are also observed in the northwestern Ross Sea where the Transantarctic Mountains are the topographic barrier (O'Connor et al. 1994). Barrier winds have also been observed along the southwest coast of Greenland during the boreal summer, where they have a significant role in melting of ice at the margin of the ice sheet (van den Broeke and Gallee 1996).

There is a concern that the NCEP reanalysis and other global analyses may significantly under-represent high wind speed events that occur in the vicinity of Greenland as a result of their relatively narrow width compared to the coarse $(\sim 200 \mathrm{~km})$ resolution of the reanalyses (Moore 2003; Pickart et al. 2003b); as well as failing to capture the magnitude, detailed structure, and time span of these mesoscale wind events. Note that these failings would lead to poor atmospheric forcing fields for any ocean modeling studies (Bacon et al. 2003; Pickart et al. 2003b). To address this concern, here we will use $5 \mathrm{yr}$ of the high-resolution surface wind field observations from the SeaWinds scatterometer on the QuikSCAT satellite to develop a climatology of high surface wind speed events around Greenland. This new scatterometer has a number of advantages over its predecessors, as described in detail in the next section, making it the most suitable dataset currently available for such a study. In section 3, we will present the statistics of the surface wind field near Greenland and a composite analysis of the circulation associated with high wind speed events in the region. In section 4, we will provide a discussion of the flow dynamics responsible for these high wind events and follow this in section 5 with our conclusions.

\section{Data and methods}

The SeaWinds Ku-band microwave scatterometer is carried on board the Quick Scatterometer (QuikSCAT) satellite, launched in June 1999. Surface wind speed and direction, usually adjusted to a 10-m height, are inferred from backscatter measurements through the use of a geophysical model function (Ebuchi et al. 2002). Validation with ocean buoy data has shown that these functions are able to meet the design specifications of the instrument, which was to measure the surface wind to an accuracy better than $2 \mathrm{~m} \mathrm{~s}^{-1}$ in magnitude and $20^{\circ}$ in direction (Ebuchi et al. 2002; Pickett et al. 2003). Concern has been raised that one such function, the Ku-2000 function developed by Remote Sensing Systems, Inc., results in a significant overestimation of surface wind speeds in high wind conditions (Ebuchi et al. 2002). It has been reported that subsequent revisions to the model, the so-called Ku-2001 model, have corrected this bias (Wentz et al. 2001). Indeed, a comparison between observations at Macquarie Island in the Southern Ocean and surface winds retrieved from the SeaWinds data with the $\mathrm{Ku}-2001$ function indicate good overall agreement especially during high wind speed events (Yuan 2004). An advantage of the approach taken by Remote Sensing Systems in their processing of the SeaWinds data is the use of contemporaneous passive microwave data from the Defense Meteorological Satellite Program (DMSP) and the Tropical Rainfall Measuring Mission (TRMM) satellites to improve the identification of contamination resulting from the presence of heavy precipitation and/or sea ice (Wentz et al. 2001; Ebuchi et al. 2002). The latter is the primary concern at the latitudes of interest in this paper.

The SeaWinds instrument has several advantages over earlier scatterometers that makes it ideal for our purposes. Most important is its high spatial resolution, $0.25^{\circ}$ or approximately $25 \mathrm{~km}$, as well as its relatively large swath width, which allow for a daily sampling of $90 \%$ of the World Ocean (Chelton et al. 2004). At high latitudes, poleward of approximately $45^{\circ}$, the instrument samples $100 \%$ of the ocean surface on a twicedaily basis. This allows for the temporal sampling of 
rapidly developing mesoscale weather systems, which is not, in general, possible at lower latitudes (Chelton et al. 2004).

For this paper, we use version 3 of the twice-daily 10-m wind speed and direction data from the SeaWinds scatterometer as processed and archived by Remote Sensing Systems, Inc., using the $\mathrm{Ku}-2001$ geophysical model function (Wentz et al., 2001). Our focus is on the winter months as this is the period of time when wind speeds over the North Atlantic are highest (Isemer and Hasse 1991; Moore 2003). In particular, we considered the months of December-February (DJF) for the period for which we have SeaWinds data (i.e., December 1999 through February 2004). The data was processed at its full resolution of $0.25^{\circ}$. To eliminate biases resulting from temporal undersampling due to the presence of sea ice, we calculated the various statistics used to describe the $10-\mathrm{m}$ wind field at those grid points that were ice free at least $85 \%$ of the time. As a result, grid squares affected by sea ice more than $15 \%$ of the time are blanked out in all figures. Motivated by the studies outlined in the introduction, our focus is on the area surrounding southern Greenland, south of approximately $70^{\circ} \mathrm{N}$ (Fig. 1).

\section{Results}

\section{a. Statistics of the 10-m wind field near Greenland}

In Fig. 2, we present the winter-mean $10-\mathrm{m}$ vector wind field and its magnitude as derived form the QuikSCAT data. The overall sense of this field is one of a cyclonic circulation that is modified due to the presence of Greenland. Such a cyclonic circulation would be expected given the presence of the climatological "Icelandic" low in the region. The magnitude of this field is highest along the southeast coast of Greenland where there exists northerly or northeasterly flow. A local maxima in the magnitude of this field occurs in the vicinity of Cape Farewell; while downwind of Cape Farewell, there exists a region that extends beyond Iceland where the magnitude of this field is less than $1 \mathrm{~m} \mathrm{~s}^{-1}$.

A very different picture arises when one considers the winter-mean $10-\mathrm{m}$ wind speed field, presented in Fig. 3. The most notable feature of this field is the highly localized maxima (in excess of $15 \mathrm{~m} \mathrm{~s}^{-1}$ ) just to the south and east of Cape Farewell. Other local maxima in the wind speed field exist along the southeast coast of Greenland near Denmark Strait at approximately $65^{\circ}$ and $67^{\circ} \mathrm{N}$. In what follows, we will refer to these two locations as Denmark Strait South and Denmark Strait North respectively. Minima in the field exist along the southwest coast of Greenland, as well as

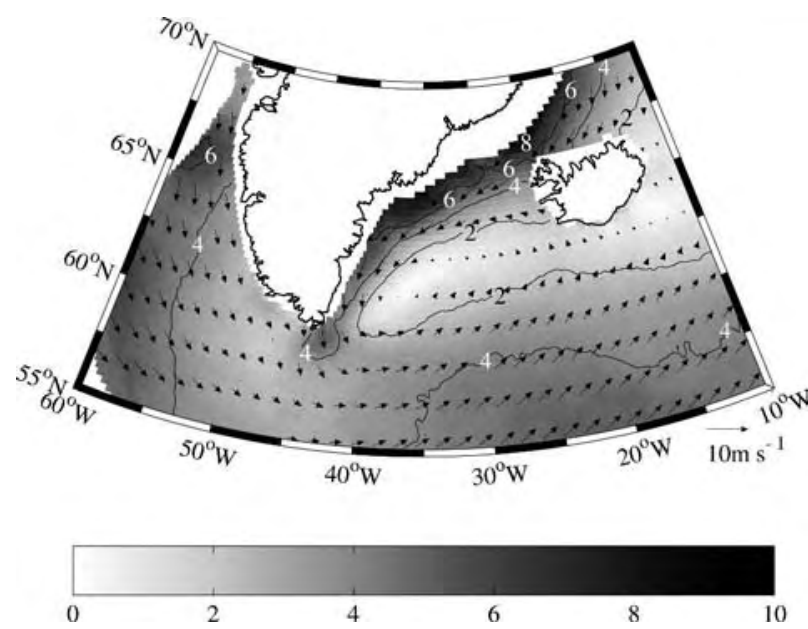

FIG. 2. The winter (DJF) mean of $10-\mathrm{m}$ wind field (vectors, $\mathrm{m} \mathrm{s}^{-1}$ ) and its magnitude (shading, $\mathrm{m} \mathrm{s}^{-1}$ ) from the QuikSCAT dataset (1999-2004). The 10-m wind field is shown at every sixth grid point (i.e., every $1.5^{\circ}$ ).

in the region extending in a northeasterly direction from Cape Farewell to north of Iceland. This latter region was also identified in Fig. 2 as a region of low $10-\mathrm{m}$ winds. The order of magnitude difference between the magnitude of the 10-m wind field $\left(\sim 1 \mathrm{~m} \mathrm{~s}^{-1}\right)$ and the $10-\mathrm{m}$ wind speed field $\left(\sim 10 \mathrm{~m} \mathrm{~s}^{-1}\right)$ in this region attests to the highly variable wind direction here and is probably reflective of the presence of a major storm track (Hoskins and Hodges 2002). In addition, the somewhat reduced mean wind speed between Cape Farewell and Iceland may be due to this being a wake area for any westerly flows impinging on the topographic barrier of Greenland (Petersen et al. 2003).

One consequence of the generalized triangle inequality (Abramowitz and Stegun 1965) is that the winter-

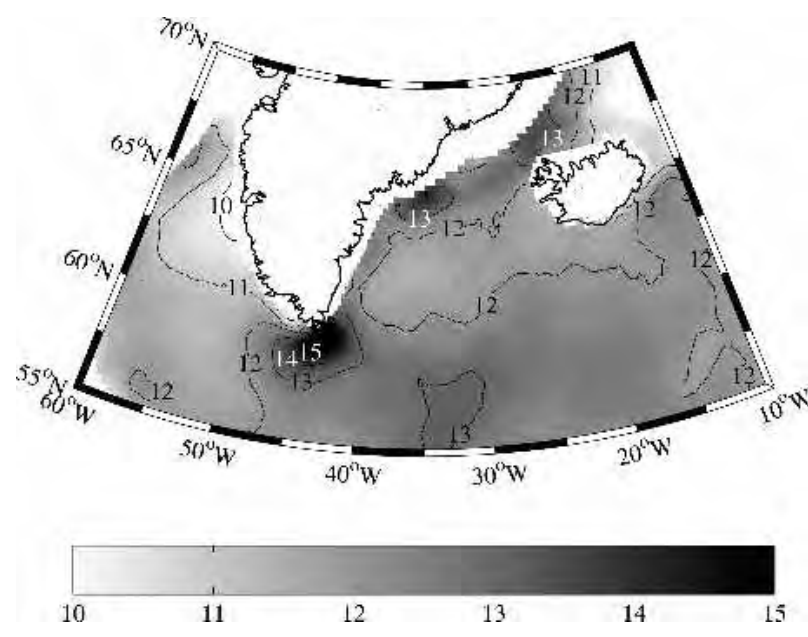

FIG. 3. The winter (DJF) mean of the 10-m wind speed field $\left(\mathrm{m} \mathrm{s}^{-1}\right)$ from the QuikSCAT dataset (1999-2004). 
mean 10-m wind speed field will always be greater than or equal to the magnitude of the winter-mean $10-\mathrm{m}$ wind field. The ratio of these two fields is defined as the directional constancy (Bromwich 1989) and is shown in Fig. 4. Values close to one indicate a constancy in the direction of the mean wind, while values close to zero indicate unsteadiness in wind direction. From this figure, we see that the southeast coast of Greenland is a region characterized by high directional constancy. From Fig. 2, we note that the wind in this region is parallel to the coast with the barrier to the right, conditions consistent with barrier flow (King and Turner 1997). The Labrador Sea is another region where there is relatively high directional constancy and from Fig. 2, one can see that this is associated with northerly and northwesterly flow. Again in this region, the high topography of Greenland contributes to this constancy in wind direction through a channeling of the flow out of the Labrador Sea. As discussed above, the region extending from Cape Farewell in a northeasterly direction toward Iceland and beyond is characterized by a low directional constancy. In addition, there is a localized region to the south and west of Cape Farewell where the directional constancy is small. As will be discussed below, this is associated with the presence of tip jets and reverse tip jets and the ensuing bimodal nature of the wind field off Cape Farewell (Moore 2003).

We now turn our attention to a characterization of the variability of the $10-\mathrm{m}$ wind speed. We present in Fig. 5 the standard deviation of the $10-\mathrm{m}$ wind speed field during the winter months from the twice-daily QuikSCAT data. The region near Cape Farewell as well as the Denmark Strait South and Denmark Strait North locations identified in Fig. 3 as regions with high mean wind speeds are seen from Fig. 5 as also being
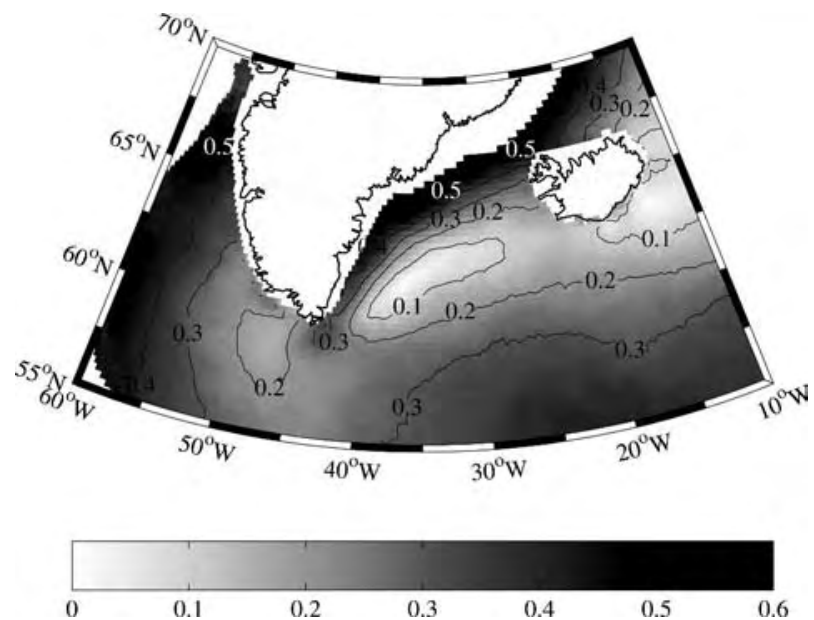

FIG. 4. The directional constancy of the winter (DJF) mean 10-m wind field from the QuikSCAT dataset (1999-2004).

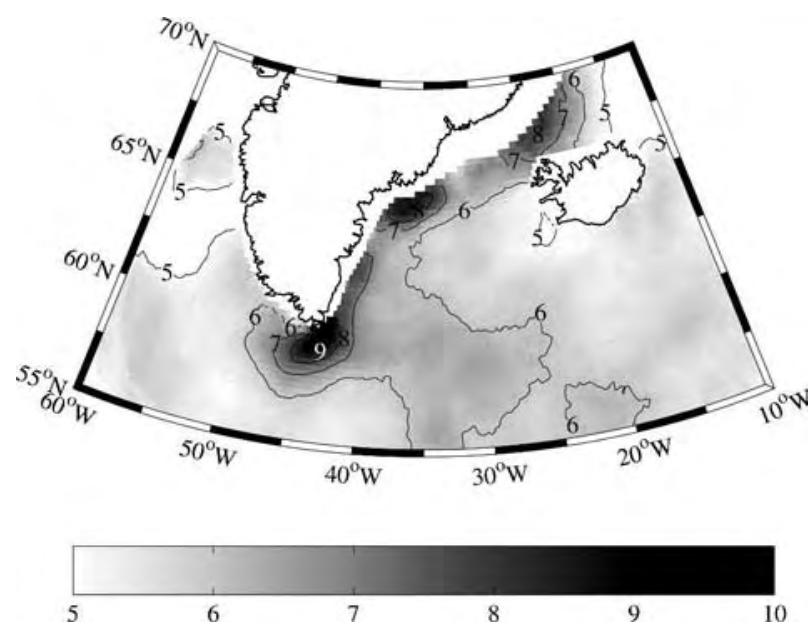

FIG. 5. The standard deviation of the winter (DJF) 10-m wind speed field $\left(\mathrm{m} \mathrm{s}^{-1}\right)$ from the QuikSCAT dataset (1999-2004).

regions of high variability in wind speed. In all three regions, the standard deviation of the $10-\mathrm{m}$ wind speed during the winter months is in excess of $7 \mathrm{~m} \mathrm{~s}^{-1}$ over a relatively confined area. The southwest and northeast coast of Iceland as well as the southwest coast of Greenland are regions where the variability in the $10-\mathrm{m}$ wind speed during the winter months is low at $5 \mathrm{~m} \mathrm{~s}^{-1}$. It is interesting to note that the region between Cape Farewell and Iceland that was prominently identified in Figs. 2 and 4 as being a region of low wind speed and low constancy does not appear as being a region of high variability in the wind speed field. This is consistent with the premise that that low mean winds in the region are the result of variability in wind direction associated with the passage of synoptic-scale low pressure systems.

Another approach that provides information about extreme values is to calculate the probability that a given wind speed will be exceeded (Ross 1995; Moore 2003). Figure 6 shows such a calculation for the QuikSCAT data. The cutoff wind speed was rather arbitrarily selected as $25 \mathrm{~m} \mathrm{~s}^{-1}$; although qualitatively similar patterns were found for other cutoff wind speeds. From this figure, one can see that the southeast coast of Greenland as well as Cape Farewell are regions where the probability of observing high wind speeds is relatively large during the winter months. The highest probabilities occur near Cape Farewell where wind speeds in excess of $25 \mathrm{~m} \mathrm{~s}^{-1}$ occur approximately $15 \%$ of the time. Embedded within the region of high probability that extends along the southeast coast of Greenland are two local maxima in the previously identified Denmark Strait South and North locations. The latter one is slightly obscured by the variable sea ice cover in the region. In both of these regions, the probability of observing winds in excess of $25 \mathrm{~m} \mathrm{~s}^{-1}$ is approximately 

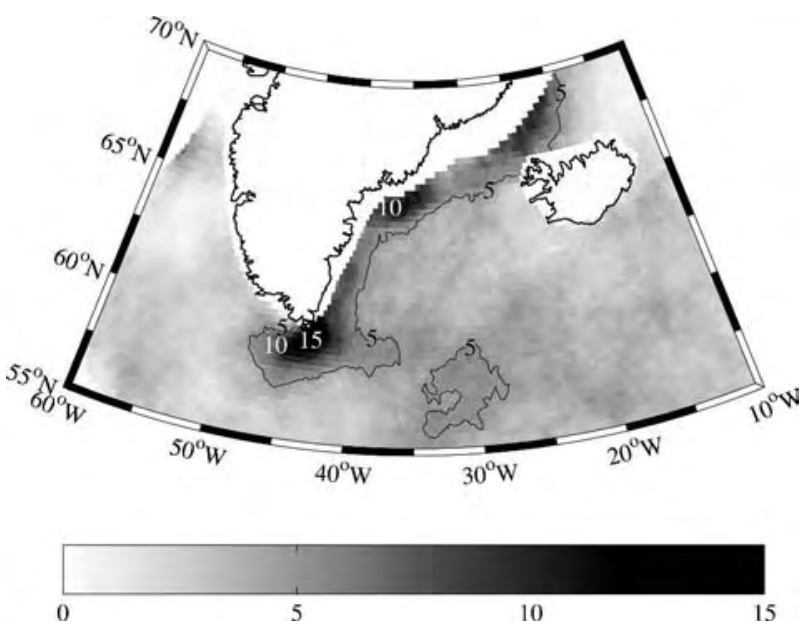

FIG. 6. The probabililty (\%) of observing a $10-\mathrm{m}$ wind speed in excess of $25 \mathrm{~m} \mathrm{~s}^{-1}$ in the QuikSCAT winter (DJF) dataset (1999-2004).

$10 \%$. If one considers a higher threshold, $33 \mathrm{~m} \mathrm{~s}^{-1}$ or hurricane-force winds, then the probability of observance near Cape Farewell drops to approximately 6\%, while in the two regions along Greenland's southeast coast it drops to approximately $3 \%-4 \%$. Aside from the Greenland coast, the other area where one is likely to experience high winds is in the central North Atlantic (around $57^{\circ} \mathrm{N}, 30^{\circ} \mathrm{W}$ ). This is along the southern flank of the primary synoptic-scale storm track (Hoskins and Hodges 2002). The region to the northeast of Iceland as well as the northwest coast of Greenland and adjoining areas of the Labrador Sea stand out as regions where the probability of observing high winds is low.

We finish our presentation of the statistics of the $10-\mathrm{m}$ wind field with a more detailed view of the winds at the three locations identified above as being ones where high wind speed events are common: Cape Farewell, Denmark Strait South, and Denmark Strait North. Wind roses derived from the QuikSCAT data for these three locations are shown in Fig. 7. With regard to Cape Farewell, the wind regime is bimodal with winds coming most frequently from the either the west and westnorthwest or the north-northeast and northeast. These are also the directions of the strongest wind speeds, although high winds can come from any direction. Cape Farewell rarely experiences low wind speeds in winter, indeed the $0-10 \mathrm{~m} \mathrm{~s}^{-1}$ bin is the least frequently occupied in every direction. Using the coarser resolution NCEP reanalysis data, Moore (2003) identified these two clusters, on the basis of a bimodalilty in the zonal wind distribution, as so-called tip jet and reverse tip jet events. From Fig. 7a, it is clear that the high wind speed events associated with easterly flow have a significant a)

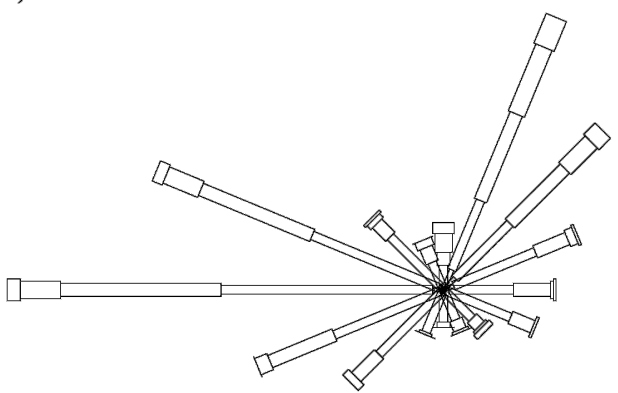

b)

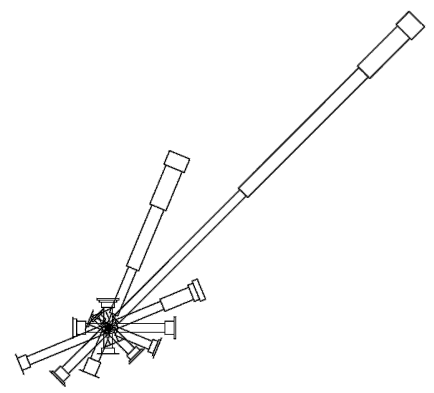

c)

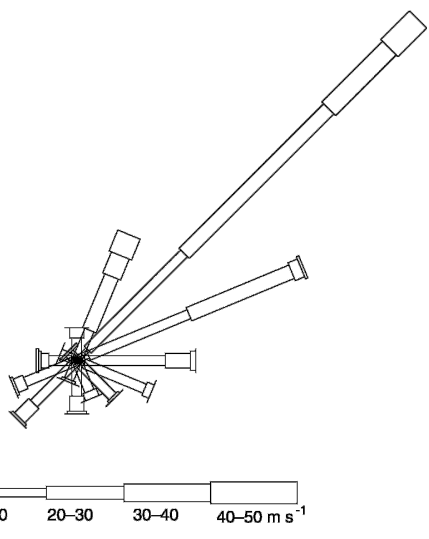

FIG. 7. Wind roses generated from QuikSCAT winter (DJF 1999-2004) observations at (a) Cape Farewell $\left(59.375^{\circ} \mathrm{N}\right.$, $\left.42.875^{\circ} \mathrm{W}\right)$, (b) Denmark Strait South $\left(65.375^{\circ} \mathrm{N}, 34.875^{\circ} \mathrm{W}\right)$, and (c) Denmark Strait North $\left(67.125^{\circ} \mathrm{N}, 25.125^{\circ} \mathrm{W}\right)$. The wind direction is divided into $22.5^{\circ}$ bins (i.e., from the N, NNE, NE, etc.) and the wind speed is divided into $10 \mathrm{~m} \mathrm{~s}^{-1}$ bins from 0 to $50 \mathrm{~m} \mathrm{~s}^{-1}$. The width of the bar is proportional to the wind speed and the length is proportional to the frequency.

meridional component, resulting in reverse tip jet events that are characterized by northeasterly or northnortheasterly flow.

The wind regimes at the two Denmark Strait locations are essentially the same, a unimodal preferred direction centered on the northeast, parallel to the coastal topography (Figs. 7b and 7c). The highest frequency of strong winds is also from the northeast, although again strong winds can come from any direction 
TABLE 1. Locations of each high wind speed feature and the number of events that make up each composite (i.e., Figs. 8, 10, 12, and 13).

\begin{tabular}{llccc}
\hline \hline \multicolumn{1}{c}{ Feature } & \multicolumn{1}{c}{ Location } & $\begin{array}{c}\text { Latitude } \\
\left({ }^{\circ} \mathrm{N}\right)\end{array}$ & $\begin{array}{c}\text { Longitude } \\
\left({ }^{\circ} \mathrm{W}\right)\end{array}$ & $\begin{array}{c}\text { Number } \\
\text { composite }\end{array}$ \\
\hline Tip jet & Cape Farewell & 59.375 & 42.875 & 27 \\
Reverse tip jet & Cape Farewell & 59.375 & 42.875 & 50 \\
Barrier flow & Denmark Strait South & 65.375 & 34.875 & 47 \\
Barrier flow & Denmark Strait North & 67.125 & 25.125 & 19 \\
\hline
\end{tabular}

except the northwest (directly off Greenland). As was the case for Cape Farewell, the Denmark Strait rarely experiences wind speeds less than $10 \mathrm{~m} \mathrm{~s}^{-1}$ in winter.

\section{b. Composite analysis of high wind speed events}

In this section, we will use a compositing technique to identify the synoptic-scale circulation patterns associated with the four classes of high wind events identified in the previous section: tip jets, reverse tip jets, and barrier wind events at the south and north of Denmark Strait. A cutoff wind speed, in this instance $25 \mathrm{~m} \mathrm{~s}^{-1}$, was selected to identify the high wind speed events. For those events in which the criterion was met for an extended period of time, the time of maximum wind speed was selected so as to minimize biases introduced through the multiple sampling of a single event. For each of the four classes, a composite of the 10-m wind field over the North Atlantic was created from these events. The statistical significance of the composites was assessed through a resampling technique that makes use of randomly generated composites from the same parent population to estimate the underlying probability distribution (Gershunov and Barnett 1998; Moore et al. 2003). The composite figures only shade those grid points where the $10-\mathrm{m}$ wind speed is statistically significant at the $99 \%$ level. Table 1 contains further information on the four populations of high wind speed events to be discussed.

In Fig. 8, we show the 10-m wind field associated with tip jet events near Cape Farewell. The overall picture is that tip jets are associated with a statistically significant cyclonic circulation over much of the Atlantic north of $50^{\circ} \mathrm{N}$ with a center situated to the north and east of Cape Farewell approximately halfway to Iceland. The center of the circulation, is not particularly well defined but does stand out as a region of low wind speeds that are not statistically significant. The highest wind speeds occur immediately to the south and east of Cape Farewell. The region of elevated wind speeds, in excess of $15 \mathrm{~m} \mathrm{~s}^{-1}$, extends in a southeasterly direction from the northwest of Cape Farewell over a span of approximately $10^{\circ}$ of longitude. This region of high wind speed is asymmetric in that the horizontal shear on its southern flank is considerably weaker as compared to that on its northern flank. There is evidence of a convergence in the 10-m wind field in this region of high wind speeds. Upwind of Cape Farewell over the Labrador Sea there is also evidence of flow distortion that is associated with the high topography of Greenland.

In Fig. 9, we present a Moderate Resolution Imaging Spectrometer (MODIS) visible image of a typical tip jet event contained in the composite. It confirms many of the features identified in the composite. The stratiform cloud field to the northeast of Cape Farewell is associated with the low pressure system farther to the northeast that is responsible for the background cyclonic circulation. While to the south and west of Greenland there is low-level convective cloud, some of which is organized into two-dimensional "cloud streets" approximately in the direction of the surface winds. There exists evidence of flow distortion to the northwest of Cape Farewell as well as clouds southeast that are most likely associated with low-level convergence in the tip jet.



FIG. 8. The composite 10-m wind field from the QuikSCAT dataset associated with forward tip jet events for the winter (DJF) 1999-2004. The field is shown in those regions where the corresponding $10-\mathrm{m}$ wind speed is statistically significant at the $99 \%$ level. In addition, the 10-m wind field is shown at every sixth grid point (i.e., every $1.5^{\circ}$ ). Shading indicates those regions where the $10-\mathrm{m}$ wind speed is in excess of $15 \mathrm{~m} \mathrm{~s}^{-1}$. 


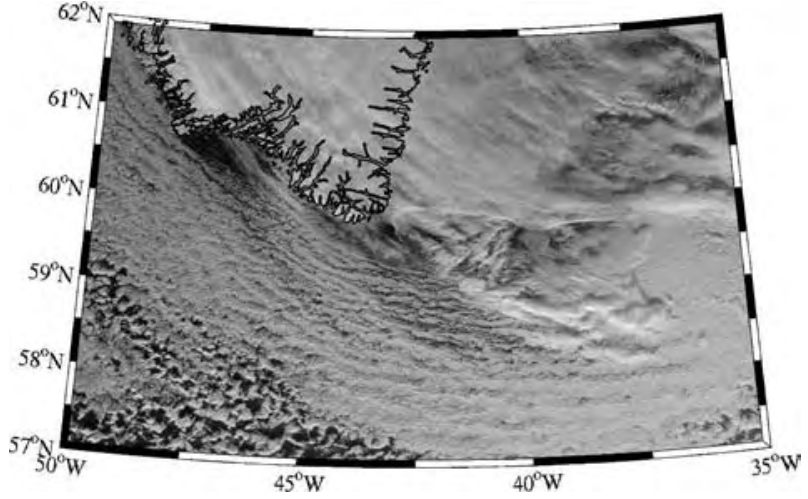

FIG. 9. MODIS visible image of a tip jet event at 1500 UTC 25 Jan 2001

In Fig. 10, we show the 10-m wind field associated with reverse tip jet events near Cape Farewell. The overall picture is markedly different from that associated with tip jets (Fig. 8). In this instance there is a broad meridional region centered on the longitude of Cape Farewell in which there is a statistically significant low-level cyclonic circulation associated with the reverse tip jet events. The center of the circulation is again not well defined but in this case is situated to the south of Cape Farewell. As compared to what occurred for the tip jet events, the region of highest wind speeds is considerably more compact in area. There appears to be an anticyclonic curvature to the wind field along the axis of the jet at Cape Farewell. Along the southeast coast of Greenland, there appears to be barrier flow. Over the Labrador Sea, there is a westerly deflection of the wind field that is associated with the events; in other words, the statistically significant vectors in this area are deflected from making a broadly cyclonic pattern.

In Fig. 11, we present a MODIS visible image of a

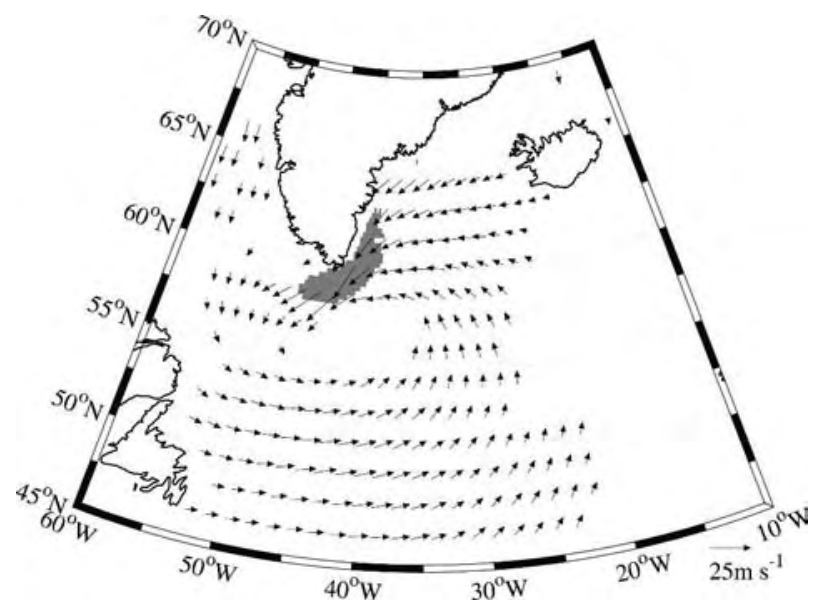

FIG. 10. As in Fig. 8 but associated with reverse tip jet events. typical reverse tip jet event contained in the composite. The most striking feature of this image is the anticyclonic curvature of the cloud feature that extends from the southeast coast of Greenland around Cape Farewell and into the Labrador Sea. The absence of clouds to the northwest of Cape Farewell is a reflection of the shadowing effect of the high topography of southern Greenland. The stratiform cloud to the southwest of Cape Farewell is associated with the low pressure system responsible with the background circulation.

In Fig. 12, we present the 10-m wind field associated with high wind speed barrier flow events at the Denmark Strait South location. The cyclonic circulation associated with the high wind speed events at this location is statistically significant over much of the North Atlantic and has a well-defined center to the northeast of Cape Farewell. A turning and acceleration of the 10-m wind along the southeast coast of Greenland as the cyclonic circulation interacts with the high topography of the plateau is apparent. The bowing out of the 10 $\mathrm{m} \mathrm{s}^{-1}$ composite wind speed contour toward the west coast of Iceland and flow distortion along its south coast suggests that the proximity of Iceland may play a role in the existence of the isolated wind speed maximum at this location. The cyclonic curvature of the coastline in the vicinity of the Denmark Strait South location may also contribute to its existence. Over the Labrador Sea, there exists no indication of the sort of flow distortion seen in the tip jet and reverse tip jet events (Figs. 8 and 10); in other words the overall pattern of the composite flow is almost exactly circular.

We complete this section with the presentation in Fig. 13 of the 10-m wind field associated with high wind speed barrier flow events at the Denmark Strait North location. Please note the change in domain from that used in Figs. 8, 10, and 12. As in the other composites,

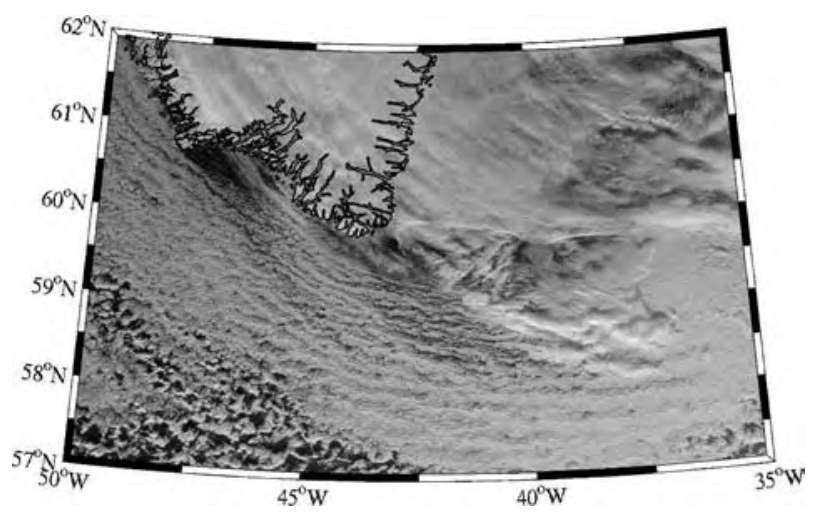

FIG. 11. As in Fig. 9 but an image of a reverse tip jet event at 1430 UTC 21 Dec 2000. 


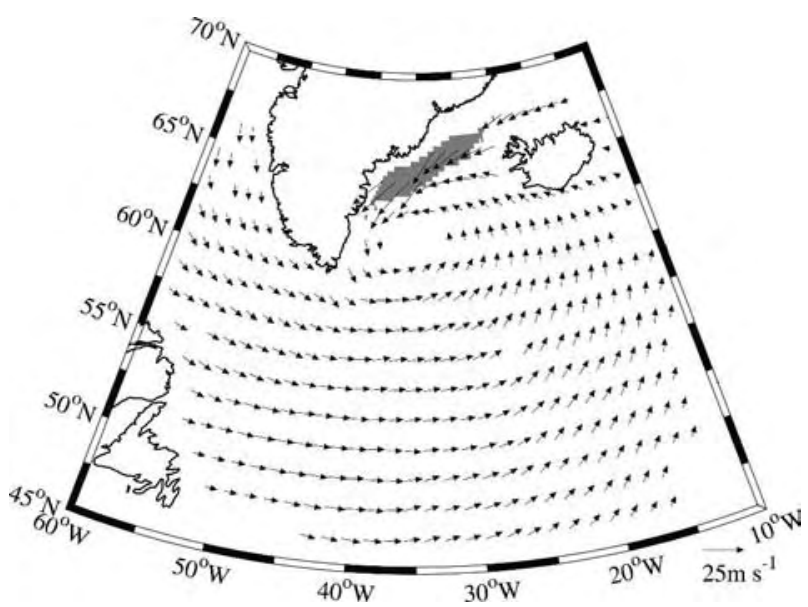

FIG. 12. As in Fig. 8 but associated with barrier flow at the Denmark Strait South location.

there is a statistically significant cyclonic circulation associated with high wind events in this location. In this instance, the center of the circulation is over Iceland. There is clear evidence of convergence and channeling of the 10-m wind field near the northern end of Denmark Strait. There is also a region of high wind speed, in excess of $15 \mathrm{~m} \mathrm{~s}^{-1}$, on the southern flank of the cyclonic circulation to the southwest of Iceland.

\section{Dynamics of high wind speed events near Greenland}

In this section, we will discuss the dynamical processes through which the interaction of a background cyclonic circulation with the topography of Greenland

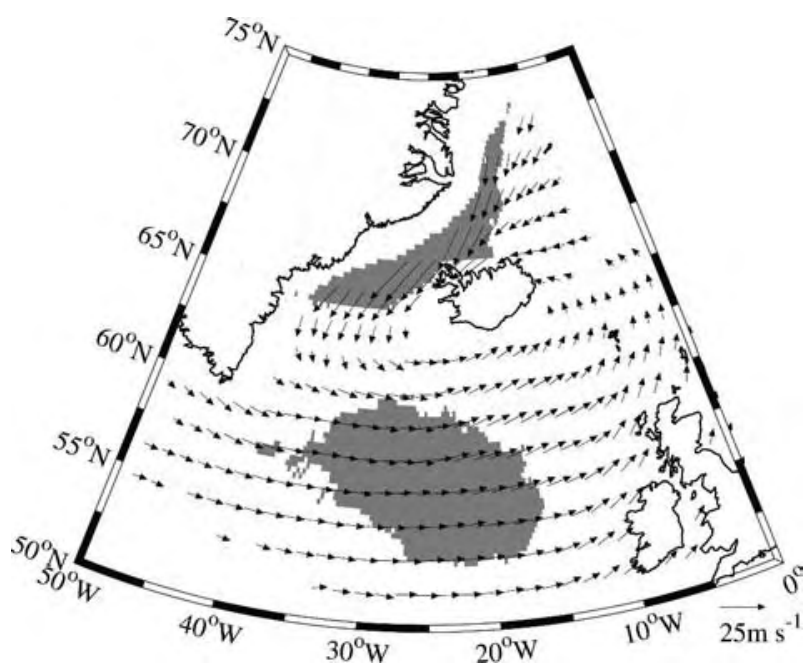

FIG. 13. As in Fig. 8 but associated with barrier flow at the Denmark Strait North location. results in high wind speed events. Theories exist for tip jets and barrier flow and we will begin our discussion with these phenomena.

\section{a. Tip jet events}

Doyle and Shapiro (1999) proposed that tip jets were the result of the conservation of the Bernoulli function during orographic descent down the lee side of the plateau near Cape Farewell that resulted in an acceleration of the wind. Doyle and Shapiro (1999) also recognized the possible importance of the acceleration of the surface wind that results from the deflection of air parcels around the southern tip of Greenland, a feature recognized for many years in theories and idealized models of flow impinging on an isolated mountain (Smith 1989) and investigated more recently with respect to Greenland by Petersen et al. (2003). The contributions of these two mechanisims, orographic descent and flow splitting, to any particular tip jet event appears to depend on the background atmospheric state, for example, the Froude number (or dimensionless mountain height) and the Rossby number. Here, as we are considering only the surface wind field, we cannot unfortunately comment in detail on these mechanisms, other than to note that we do see high wind speeds upstream of Cape Farewell (Fig. 8) that suggest that an acceleration of the wind through the deflection of air parcels is a robust feature of tip jets. It is likely to be the case that our tip jet composite is made up of events forced by a range of the two mechanisms. It should be emphasized that the Doyle and Shapiro (1999) analysis considered the distortion of a zonally uniform flow by Greenland-like plateaus and as a result did not consider the impact that a background cyclonic circulation would have on the formation of tip jets.

\section{b. Barrier flow events}

Barrier flows typically occurs in situations when cold and stably stratified air is forced, through the action of the prevailing synoptic-scale flow, toward a topographic barrier (King and Turner 1997). If the Froude number is less one, ${ }^{1}$ then the air is unable to cross the barrier, resulting in a damming of the air against the barrier and the development of a pressure gradient per-

\footnotetext{
${ }^{1}$ This applies for barriers of infinite length. Numerical modeling experiments of elliptical barriers of similar proportions to Greenland have shown a more gradual change from flow over a barrier to flow around a barrier at a Froude number of approximately 0.5 (e.g., Olafsson and Bougeault 1996; Petersen et al. 2003).
} 
pendicular to the barrier. The resultant flow parallel to the barrier is in approximate geostrophic balance (Schwerdtfeger 1975; Parish 1983), that is,

$$
\mathbf{F}_{p}+\mathbf{F}_{c}=0
$$

where $\mathbf{F}_{p}$ is the pressure gradient force and $\mathbf{F}_{c}$ is the Coriolis force.

In natural coordinates with $\mathbf{s}$ being directed in the direction of the flow and $\mathbf{n}$ perpendicular to the flow, then

$$
\begin{aligned}
& \mathbf{F}_{p}=-\frac{1}{\rho} \frac{\partial P}{\partial n} \mathbf{n}, \\
& \mathbf{F}_{c}=-f V_{g} \mathbf{n},
\end{aligned}
$$

where $\rho$ is the density, $P$ is the pressure, $f$ is the Coriolis parameter and $V_{g}$ is the geostrophic velocity along the barrier, that is, in the $\mathbf{s}$ direction. Therefore,

$$
V_{g}=-\frac{1}{f \rho} \frac{\partial P}{\partial n} .
$$

Typical Froude numbers $(\mathrm{Fr})$ along the southeast coast of Greenland are estimated to be on the order of ${ }^{2}$ 0.3 , so the possibility for barrier flow exists. Furthermore theoretical considerations (Overland 1984) show that the barrier effect may be significant within a Rossby radius of deformation, defined as

$$
R_{R}=\frac{V_{g}}{f \mathrm{Fr}},
$$

of the topographic barrier. For a Froude number of 0.3 and the Coriolis parameter of $1.2 \times 10^{-4} \mathrm{~s}^{-1}$, then a 15 $\mathrm{m} \mathrm{s}^{-1}$ wind results in $R_{R} \sim=400 \mathrm{~km}$. As can be seen from Figs. 2, 4, 12 and 13; it is clear that barrier flow exists within a band along the southeast coast of Greenland of this approximate width.

There is, however, the question of why two regions exist, to the south and north of Denmark Strait, where high wind speed barrier flow preferentially occurs. As discussed the presence of Iceland appears to be a factor. Its presence would, through the Bernoulli effect, result in an increase in the advection of air toward the barrier, leading to a larger pressure gradient and higher geostrophic velocity through (4). A similar acceleration of the wind through the Dover Straits is observed to be a robust feature (Capon 2003). Katabatic flow down the large fiords along Greenland's southeast coast may also contribute to the barrier flow in this region through an

\footnotetext{
${ }^{2} \mathrm{We}$ assumed a surface temperature of $260 \mathrm{~K}$, a barrier height from 2 to $3 \mathrm{~km}$, a surface velocity from 10 to $20 \mathrm{~m} \mathrm{~s}^{-1}$, and a dry adiabatic lapse rate, resulting in a Froude number around 0.3 (King and Turner 1997).
}

anticyclonic turning that occurs once the airflow leaves the fiords (Klein and Heinemann 2002).

\section{c. Reverse tip jet events}

As can clearly be seen from Fig. 10, reverse tip jets are typically associated with barrier flow immediately to the north of Cape Farewell. Therefore, what requires an explanation is the acceleration that results in the highest wind speeds in the immediate vicinity of the Cape as well as the anticyclonic curvature to the wind seen in Figs. 10 and 11. We begin with the former and assume anticyclonic curvature, the appropriate force balance is then that of a gradient wind balance, which in natural coordinates, is

$$
F_{p}+F_{c}^{\prime}+F_{r}=0
$$

where $F_{p}$ is as above, $F_{c}^{\prime}=-f V \mathbf{n}$ and, $F_{r}$ is the cyclostrophic force.

Assuming a radius of curvature $\mathrm{R},>0$ for cyclonic flow and $<0$ for anti-cyclonic flow, then

$$
F_{r}=-V^{2} / R \mathbf{n} \text {. }
$$

Therefore, (6) reduces to

$$
\left(V-V_{g}\right)=-V^{2} / f R \text {. }
$$

For anticyclonic flow, it follows that $V>V_{g}$, so one would expect the flow in the core of the reverse jet to be supergeostrophic, suggesting an acceleration at Cape Farewell.

Making the assumption of a zero background (synoptic-scale) pressure gradient perpendicular to the barrier (i.e., in the $\mathbf{n}$ direction) and following the arguments of Parish and Schwerdtfeger (1977), the absence of the topographically induced pressure gradient $F_{p}$ immediately south of Cape Farewell results in an inertial force balance:

$$
\begin{aligned}
F_{c}+F_{r} & =0, \\
-f V & =V^{2} / \mathrm{R},
\end{aligned}
$$

or

$$
R=-V / f \text {. }
$$

From the composite shown in Fig. 10, typical wind speeds in the core of the jet are on the order of $25 \mathrm{~m} \mathrm{~s}^{-1}$ and result in an anticyclonic radius of curvature that is on the order of $200 \mathrm{~km}$. This is consistent with the composite as well as the satellite image shown in Fig. 11. In reality, background pressure gradients will of course modify these idealized force balances; however, it is interesting that the composite and satellite imagery indicate that they appear to hold. This linear relationship between jet core velocity and radius of curvature may therefore provide for a relatively simple diagnostic for jet core velocities. 


\section{Conclusions}

Greenland plays a significant role in the circulation of the North Atlantic as a result of its high topography and ice-covered surface (Scorer 1988; Petersen et al. 2003; Petersen et al. 2004). In its immediate vicinity, there is growing evidence that high wind speed events are a common occurrence that play a role in severe weather (Mertins 1976; Doyle and Shapiro 1999; Klein and Heinemann 2002; Mills and Anderson 2003) as well as being important for forcing oceanic circulations (Bacon 1997; Lavender et al. 2000; Spall and Pickart 2003).

In this paper we have used the $10-\mathrm{m}$ wind field dataset derived from the NASA Jet Propulsion Laboratory (JPL) SeaWinds scatterometer aboard the QuikSCAT satellite to develop a climatology of high speed events in the vicinity of Greenland. Our focus is on the winter months when previous studies have indicated that $10-\mathrm{m}$ wind speeds are highest and when the impact of the winds on the ocean is greatest.

The high spatial resolution of the QuikSCAT winds, $0.25^{\circ}$, allows for an unprecedented view of the flow distortion associated with Greenland that results in these high wind speed events. There is however evidence from very high resolution Synthetic Aperature Radar imagery of finer-scale structure within these flows that is not captured in the QuikSCAT data (Horstmann et al. 2000a,b).

Our analysis is in general agreement with an earlier study that made use of the lower-resolution NCEP reanalysis to characterize high wind events near Cape Farewell (Moore 2003). In particular, we have confirmed that the Cape Farewell region is one where high wind speed events are common and that these events fall into two distinct categories: tip jet events and reverse tip jet events. The common occurrence of high winds at two locations in Denmark Strait confirms a previous anecdotal account (Scorer 1988). Flow in these locations, and indeed elsewhere along the southeast coast of Greenland, occurs with the topography to the right; a characteristic consistent with barrier flow (Schwerdtfeger 1975; Parish 1982, 1983). We show that high wind speed events $\left(>25 \mathrm{~m} \mathrm{~s}^{-1}\right)$ occur up to $15 \%$ of the time at Cape Farewell and up to $10 \%$ of the time in Denmark Strait, and can reach up to $50 \mathrm{~m} \mathrm{~s}^{-1}$ in both locations.

The composite $10-\mathrm{m}$ wind fields associated with the four classes of high wind speed events that we have identified (tip jet, reverse tip jets, barrier flow in the southern Denmark Strait, and barrier flow in the northern Denmark Strait) suggest that all these events result from the interaction of a cyclonic low pressure system with the high topography of Greenland and, to a lesser extent, Iceland.

In keeping with previous work our results suggest that tip jets are caused by a combination of conservation of the Bernoulli function during orographic descent and acceleration due to flow splitting as stable air passes around Cape Farewell (Doyle and Shapiro 1999; Petersen et al. 2003); while the barrier flow along the southeast coast of Greenland is consistent with a geostrophic response to low Froude number air being forced against high topography (Parish 1983). We propose that reverse tip jets occur when barrier winds reach the barrier end and move from a geostrophic to a gradient wind balance, becoming supergeostrophic as a result of their anticyclonic curvature.

With regard to the impact that these events have on the ocean, there has been a number of recent papers highlighting the role that tip jets play in forcing deep ocean convection in the Irminger Sea (Bacon et al. 2003; Moore 2003; Pickart et al. 2003a,b). With regard to reverse tip jets, it is interesting to note that a cyclonic gyre exists in the ocean to the southwest of Cape Farewell (Lavender et al. 2000; Spall and Pickart 2003) in the region that is impacted by reverse tip jets. It is therefore tempting to draw the conclusion that the transfers of heat, moisture, and momentum associated with reverse tip jets are responsible for the presence of this recirculation. With regard to barrier winds, a northeasterly off-ice flow would bring cold air over the relatively warm waters of the Irminger Sea, transferring heat and moisture out of the sea and perhaps acting to also precondition the region for open ocean convection. The constancy in wind direction that occurs as a result of the barrier flow in the region may also play a role in the wind-driven circulation of the East Greenland Current. A detailed analysis of the impacts that tip jets, reverse tip jets, and barrier flows along the southeast coast of Greenland have on the ocean will be addressed in subsequent work.

Acknowledgments. The QuikSCAT data are produced by Remote Sensing Systems, Inc., and sponsored by the NASA Ocean Vector Winds Science Team. Data are available online at www.remss.com. G. W. K. Moore was sponsored by the Natural Sciences Research Council of Canada and the Canadian Space Agency. The authors thank Bob Pickart for suggestions that greatly contributed to this work.

\section{REFERENCES}

Abramowitz, M., and I. A. Stegun, 1965: Handbook of Mathematical Functions, with Formulas, Graphs, and Mathematical Tables. Dover Publications, 1046 pp. 
Bacon, S., 1997: Circulation and fluxes in the North Atlantic between Greenland and Ireland. J. Phys. Oceanogr., 27, 14201435.

— W. W. Gould, and Y. L. Jia, 2003: Open-ocean convection in the Irminger Sea. Geophys. Res. Lett., 30, 1246, doi:10.1029/ 2002 GL016271.

Barthelmie, R. J., and S. C. Pryor, 2003: Can satellite sampling of offshore wind speeds realistically represent wind speed distributions? J. Appl. Meteor., 42, 83-94.

Bromwich, D. H., 1989: An extraordinary katabatic wind regime at Terra-Nova Bay, Antarctica. Mon. Wea. Rev., 117, 688695.

Bunker, A. F., 1976: Computations of surface energy flux and annual air-sea interaction cycles of the North Atlantic Ocean. Mon. Wea. Rev., 104, 1122-1140.

Capon, R. A., 2003: Wind speed-up in the Dover Straits with the Met Office new dynamics model. Meteor. Appl., 10, 229-237.

Chelton, D. B., M. G. Schlax, M. H. Freilich, and R. F. Milliff, 2004: Satellite measurements reveal persistent small-scale features in ocean winds. Science, $\mathbf{3 0 3}, 978-983$.

Del Prete, R., A. Pezzoli, and G. Pezzoli, 1999: Current methods for meteorological and marine forecasting for the assistance of navigation and shipping operations. J. Navigation, 52, 104118 .

Douglas, M. W., M. A. Shapiro, L. S. Fedor, and L. Saukkonen, 1995: Research aircraft observations of a polar low at the East Greenland ice edge. Mon. Wea. Rev., 123, 5-15.

Doyle, J. D., and M. A. Shapiro, 1999: Flow response to largescale topography: The Greenland tip jet. Tellus, 51A, 728748 .

Ebuchi, N., H. C. Graber, and M. J. Caruso, 2002: Evaluation of wind vectors observed by QuikSCAT/SeaWinds using ocean buoy data. J. Atmos. Oceanic Technol., 19, 2049-2062.

Gershunov, A., and T. P. Barnett, 1998: Interdecadal modulation of ENSO teleconnections. Bull. Amer. Meteor. Soc., 79, 27152725.

Hennessey, J. P., 1977: Some aspects of wind power statistics. J. Appl. Meteor., 16, 119-128.

Horstmann, J., W. Koch, S. Lehner, and R. Tonboe, 2000a: Wind retrieval over the ocean using synthetic aperture radar with C-band HH polarization. IEEE Trans. Geosci. Remote Sens., 38, 2122-2131.

- S. Lehner, W. Koch, and R. Tonboe, 2000b: Computation of wind vectors over the ocean using spaceborne Synthetic Aperture Radar. Johns Hopkins APL Tech. Dig., 21, 100-107.

Hoskins, B. J., and K. I. Hodges, 2002: New perspectives on the Northern Hemisphere winter storm tracks. J. Atmos. Sci., 59, 1041-1061.

Isemer, H. J., and L. Hasse, 1991: The scientific Beaufort equivalent scale-Effects on wind statistics and climatological airsea flux estimates in the North Atlantic Ocean. J. Climate, 4, 819-836.

Khandekar, M. L., and V. R. Swail, 1995: Storm waves in Canadian waters-A major marine hazard. Atmos.-Ocean, 33, 329-357.

King, J. C., and J. Turner, 1997: Antarctic Meteorology and Climatology. Cambridge Atmospheric and Space Science Series, Cambridge University Press, 409 pp

Klein, T., and G. Heinemann, 2002: Interaction of katabatic winds and mesocyclones near the eastern coast of Greenland. Meteor. Appl., 9, 407-422.

Kristjansson, J. E., and H. McInnes, 1999: The impact of Green- land on cyclone evolution in the North Atlantic. Quart. $J$. Roy. Meteor. Soc., 125, 2819-2834.

Lab Sea Group, 1998: The Labrador Sea deep convection experiment. Bull. Amer. Meteor. Soc., 79, 2033-2058.

Lavender, K. L., R. E. Davis, and W. B. Owens, 2000: Mid-depth recirculation observed in the interior Labrador and Irminger Seas by direct velocity measurements. Nature, 407, 66-69.

Lynch, A. H., E. N. Cassano, J. J. Cassano, and L. R. Lestak, 2003: Case studies of high wind events in Barrow, Alaska: Climatological context and development processes. Mon. Wea. Rev., 131, 719-732.

Mailhot, J., D. Hanley, B. Bilodeau, and O. Hertzman, 1996: A numerical case study of a polar low in the Labrador Sea. Tellus, 48A, 383-402.

Mertins, H. O., 1976: Compendium of Lecture Notes in Marine Meteorology for Class III and Class IV Personnel. Secretariat of the World Meteorological Organization, $22 \mathrm{pp}$.

Mills, B. J., and M. R. Anderson, 2003: Monitoring a Piteraq storm system using DMSP imagery and QuikSCAT wind data. Preprints, 12th Conf. on Satellite Meteorology and Oceanography, Long Beach, CA, Amer. Meteor. Soc., CDROM, JP2.8.

Moore, G. W. K., 2003: Gale force winds over the Irminger Sea to the east of Cape Farewell, Greenland. Geophys. Res. Lett., 30, 1894, doi:10.1029/2003GL018012.

, and P. W. Vachon, 2002: A polar low over the Labrador Sea: Interactions with topography and an upper-level potential vorticity anomaly, and an observation by RADARSAT-1 SAR. Geophys. Res. Lett., 29, 1773, doi:10.1029/2001GL014007.

_ M. C. Reader, J. York, and S. Sathiyamoorthy, 1996: Polar lows in the Labrador Sea-A case study. Tellus, 48A, 17-40. , K. Alverson, and G. Holdsworth, 2003: The impact that elevation has on the ENSO signal in precipitation records from the Gulf of Alaska region. Climate Change, 59, 101-121.

O'Connor, W. P., D. H. Bromwich, and J. F. Carrasco, 1994: Cyclonically forced barrier winds along the Transantarctic Mountains near Ross Island. Mon. Wea. Rev., 122, 137-150.

Olafsson, H., and P. Bougeault, 1996: Nonlinear flow past an elliptic mountain ridge. J. Atmos. Sci., 53, 2465-2489.

Overland, J. E., 1984: Scale analysis of marine winds in straits and along mountainous coasts. Mon. Wea. Rev., 112, 2530-2534.

Parish, T. R., 1982: Barrier winds along the Sierra Nevada Mountains. J. Appl. Meteor., 21, 925-930.

, 1983: The influence of the Antarctic Peninsula on the windfield over the western Weddell Sea. J. Geophys. Res., 88, 2684-2692.

— Bransfield Strait-Example of inertial flow. Antarct. J. U.S., 12, 171-172.

Pavia, E. G., and J. J. O'Brien, 1986: Weibull statistics of windspeed over the ocean. J. Climate Appl. Meteor., 25, 13241332 .

Petersen, G. N., H. Olafsson, and J. E. Kristjansson, 2003: Flow in the lee of idealized mountains and Greenland. J. Atmos. Sci., 60, 2183-2195.

_ J. E. Kristjansoon, and H. Olafsson, 2004: Numerical simulations of Greenland's impact on the Northern Hemisphere winter circulation. Tellus, 56A, 102-111.

Pickart, R. S., F. Straneo, and G. W. K. Moore, 2003a: Is Labrador Sea Water formed in the Irminger basin? Deep-Sea Res., 50A, $23-52$. 
- M. A. Spall, M. H. Ribergaard, G. W. K. Moore, and R. F. Milliff, 2003b: Deep convection in the Irminger Sea forced by the Greenland tip jet. Nature, 424, 152-156.

Pickett, M. H., W. Q. Tang, L. K. Rosenfeld, and C. H. Wash, 2003: QuikSCAT satellite comparisons with nearshore buoy wind data off the U.S. West Coast. J. Atmos. Oceanic Technol., 20, 1869-1879.

Rasmussen, E. A., C. Claud, and J. F. Purdom, 1996: Labrador Sea polar lows. Global Atmos.-Ocean Syst., 4, 275-333.

Renfrew, I. A., G. W. K. Moore, P. S. Guest, and K. Bumke, 2002: A comparison of surface layer and surface turbulent flux observations over the Labrador Sea with ECMWF analyses and NCEP reanalyses. J. Phys. Oceanogr., 32, 383-400.

Ross, W. H., 1995: A peaks-over-threshold analysis of extreme wind speeds. Case Studies in Data Analysis, J. F. Gentleman and G. A. Whitmore, Eds., Springer Verlag, 262 pp.

Schwerdtfeger, W., 1975: Effect of Antarctic Peninsula on the temperature regime of the Weddell Sea. Mon. Wea. Rev., 103, $45-51$.
Scorer, R. S., 1988: Sunny Greenland. Quart. J. Roy. Meteor. Soc., 114, 3-29.

Smith, R. B., 1989: Hydrostatic air-flow over mountains. Advances in Geophysics, Vol. 31, Academic Press, 1-41.

Spall, M. A., and J. F. Price, 1998: Mesoscale variability in Denmark Strait: The PV outflow hypothesis. J. Phys. Oceanogr., 28, 1598-1623.

- and R. S. Pickart, 2003: Wind-driven recirculations and exchange in the Labrador and Irminger Seas. J. Phys. Oceanogr., 33, 1829-1845.

van den Broeke, M. R., and H. Gallee, 1996: Observation and simulation of barrier winds at the western margin of the Greenland ice sheet. Quart. J. Roy. Meteor. Soc., 122, 13651383.

Wentz, F., D. K. Smith, C. A. Mears, and C. L. Gentemann, 2001: Advanced algorithms for QuikScat and SeaWinds/AMSR. Proc. IGARSS 2001, Sydney, Australia, IEEE, 1079-1081.

Yuan, X. J., 2004: High-wind-speed evaluation in the Southern Ocean. J. Geophys. Res., 109, D13101, doi:10.1029/ 2003JD004179. 